\title{
Effects of glycyl-glutamine on the growth performance and lipid deposition in Yue-Huang broilers*
}

\author{
G. Shu, P. Gao, X.T. Zhu, Q.Y. Jiang1, P.W. Xu, G.X. Zhou, F.W. Sun \\ and W.L. Fu
}

College of Animal Science, South China Agricultural University Guangzhou, 510642, P.R. China

(Received 13 February 2007; accepted 2 May 2007)

\begin{abstract}
To investigate the effects of glycyl-glutamine (Gly-Gln) on the growth performance and body composition in Yue-Huang broilers, two hundreds and seventy 9-d-old birds were randomly allocated to 3 groups of 90 birds each, incorporating 3 cages per group. All the birds were offered a commercial starter feed supplemented with $0,0.01$ or $0.05 \mathrm{mg}$ Gly-Gln per kg for next 5 weeks, then given a commercial grower feed for another 5 weeks. The results showed that Gly-Gln could not only significantly increase the body weight of Yue-Huang broilers but also enhanced breast muscle and leg muscle yields, while it declined abdominal fat percentage in a dose-dependent manner. The concentration of triglyceride and total cholesterol (T-CHO) in serum and that of T-CHO in pectoralis major muscle were reduced with the up-regulated mRNA expression of peroxisome proliferatoractivated receptors $\alpha$ (PPAR- $\alpha$ ) and down-regulated transcript levels of acetyl-CoA carboxylase (ACC) and sterol regulatory element binding protein-2 (SREBP-2).
\end{abstract}

KEY WORDS: glycyl-glutamine, lipid metabolism, growth performance, Yue-Huang broiler

\footnotetext{
* Supported by the National Basic Research Program of China - The 973 Program, 2004CB117501; The Science and Technology Project of Guangdong Province, 2003C20204; Guangdong Provincial Natural Science Foundation of China, 04205804 and the National Foundation of Natural Sciences, 30500367

${ }^{1}$ Corresponding author: e-mail: qyjiang@scau.edu.cn
} 


\section{INTRODUCTION}

Glutamine (Gln), a non-essential amino acid, is the most abundant free amino acid in whole blood and an important respiratory fuel and nucleotide precursor for the gastrointestinal tract likewise the immune system (Melis et al., 2004). In stressed states e.g., trauma and sepsis, the intestinal uptake of Gln from the blood is significantly increased (Nemoto et al., 1996). Several lines of evidence from animal studies and controlled clinical trials has confirmed that the nutritional support with supplemental glutamine dipeptide positively influences protein synthesis (Petersson et al., 1994), nitrogen balance (Morlion et al., 1998), immune status (Powell-Tuck, 1999), gut integrity, morbidity, rehabilitation and outcome (van der Hulst et al., 1993; Chang et al., 2001).Therefore, the highly soluble glycyl-glutamine (Gly-Gln) has been widely applied in total parenteral nutrition as the carrier of Gln (Furst et al., 1997). Furthermore, a study done by our group found that Gly-Gln could significantly increase feed conversion ratio, growth performance and dramatically reduce diarrhoea occurring rate (Huang et al., 2004).

Although a lot of experiments have been conducted on the nutritional effects of Gln or Gly-Gln in mammal and rodent, little affection has beed directed at the effect of the same in avian species. The main purpose of the present study was to investigate the effects of Gly-Gln, a dipeptide on the growth performance, body composition, level of triglyceride (TG), total cholesterol (T-CHO) in serum, liver and muscle as well as determine the expression levels of lipid metabolism- associated genes in liver.

\section{MATERIAL AND METHODS}

\section{Animals, treatments and management}

Two hundreds and seventy 9-d-old Yue-Huang broilers (a local breed in the south of China) obtained from a local hatchery (Experimental Broiler Breeder Farm of South China Agricultural University, Guangzhou, China) were weighed individually and allocated to 3 groups of 90 birds each involving 3 cages per group. The birds from each cage were randomly offered a commercial starter feed (obtained from Institute of Animal Science Guangdong, Academy of Agricultural Sciences) with the composition of, \%: soya meal 26 , maize 60 , fish meal 3, bran 5.3 , rape seed oil 4.7, premix with vitamins and minerals 1 . Calculated analysis revealed the feed to contain $20 \%$ crude protein, $2.900 \mathrm{kcal} / \mathrm{kg}$ metabolizable energy, $0.52 \%$ methionine and $1.10 \%$ lysine supplemented with 0 (control), 0.01 (LCG) or 0.05 (HCG) mg glycyl-glutamine (Gly-Gln) (Tianjin Tiancheng Pharmaceutical Company, China) per kg for 5 weeks. Then, all the birds were transferred to a commercial grower feed (22\% soyabean meal and $8.7 \%$ rape seed 
oil) for 5 weeks. Feed and water were offered ad libitum. The chickens were kept with continuous light during the first 3 days and then, $16 \mathrm{~h}$ lighting daily thereafter. The room temperature was initially set at $35^{\circ} \mathrm{C}$ and was gradually reduced to $22^{\circ} \mathrm{C}$ at week 3 and kept constant thereafter.

\section{Growth performance and carcass composition}

Liveweights on a cage basis were recorded at week 3, 5, 7 and 10. At the end of the experiment, 20 birds were sacrificed to determine the abdominal fat percentage (AFP), the breast meat yield (BMY) and the leg meat yield (LMY).

\section{Serum and tissue analysis}

At week 5, 20 non-fasted birds with weight close to the average body weight were selected from each group. Blood samples were obtained from the arteria carotis after decapitation and centrifuged at $3000 \mathrm{~g}$ for $15 \mathrm{~min}$ and the sera stored at $-20^{\circ} \mathrm{C}$. About $10 \mathrm{~g}$ of pectoralis major muscle (PM) and liver were quickly excised, washed and snap frozen at $-80^{\circ} \mathrm{C}$ until analysis. The concentration of triglyceride (TG) in serum and liver, and that of total cholesterol (T-CHO) in serum and PM were measured by commercial assay kit (Nanjing Jiancheng Biological Product Co., Ltd., China). All the analyses were carried out according to the manufacturer's instructions.

\section{Quantitative reverse transcriptase polymerase chain reaction analysis}

The relative quantitative RT-PCR was performed to detect the expression level of lipid metabolism related genes (Dieffenbach et al., 2004). Total RNAs were isolated from the liver by one-step extraction method using Trizol kit (SBS Gene Co., Ltd., Peking, China) and purified by DNase I (RNase free) (TaKaRa, Japan) to eliminate the genomic DNA contamination. RNA was assessed by agarose gel electrophoresis for integrity and quantified spectrophotometrically. All cDNAs were transcripted by $10 \mathrm{U}$ MMLV (Promega, USA) and $5 \mu \mathrm{M}$ Oligo $\mathrm{dT}_{(10)}$ in each $20 \mu \mathrm{l}$ total reverse transcript reaction from $2 \mu \mathrm{g}$ total RNA. Gene specific primer pairs were designed by Primer Premier 5.0 software according to the Genbank sequences for $\beta$-actin, ACC, PPAR $\alpha$ and SREBP-2 (Table 1). The $25 \mu 1$ PCR amplification reaction system included $2 \mu 1 \mathrm{cDNA}, 1.8 \mathrm{mM} \mathrm{MgCl}_{2}$, $1 \mathrm{mM}$ dNTPs, $0.5 \mathrm{U}$ Taq enzyme (Fermentas, Lithuania), $0.5 \mu \mathrm{M}$ specific gene primer pairs and $\beta$-actin primer/competimer. PCR thermal cycling parameters were as follows 1 cycle $94^{\circ} \mathrm{C}$ for $2 \mathrm{~min}$, followed by 29 to 32 cycles, $94^{\circ} \mathrm{C}$ for $30 \mathrm{~s}, 58^{\circ} \mathrm{C}$ for $30 \mathrm{~s}$ and $72^{\circ} \mathrm{C}$ for $1 \mathrm{~min}$ with a final extension at $72^{\circ} \mathrm{C}$ for $1 \mathrm{~min}$ (details in Table 1). The abundance of each PCR amplification products on $2 \%$ agarose gel electrophoresis was analysed by image system (UVP, UK) and the genes expression levels presented as the ratio of target genes to $\beta$-actin. 
Table 1 Sequences of primer sets and PCR parameters ${ }^{1}$

\begin{tabular}{llcc}
\hline $\begin{array}{l}\text { Genes } \\
\text { GenBank accession No. }\end{array}$ & Sequence $\left(5^{\prime} \rightarrow 3^{\prime}\right)$ & $\begin{array}{c}\text { Aplicon } \\
\text { size }(\mathrm{bp})\end{array}$ & $\begin{array}{c}\text { Cycle numbers } \\
\left(\mathrm{Ratio}^{2}\right)\end{array}$ \\
\hline $\begin{array}{l}\text { ACC } \\
(\text { J03541) }\end{array}$ & FP: TCCGAGAACCCAAAACTA & 523 & 30 \\
PPAR $\alpha$ & RP: CTTCTGATGCCTGCGTTGC & & $(5: 5)$ \\
(NM_001001464) & FP: TTTGTGGGGATAAAGCCTC & 189 & 30 \\
SREBP-2 & RP: ACATTCCAACTGAAAGGCAC & & $(5: 5)$ \\
$($ GGA310769) & FP: CAACGATGCGGACCTGAA & 190 & 32 \\
$\beta$-actin & RP: CACCATGCCAAGAGCCAC & & $(5: 5)$ \\
$($ L08165) & FP: TGCTGCGCTCGTTGTTGAC & 291 & \\
\hline
\end{tabular}

${ }^{1}$ ACC - acetyl-CoA carboxylase; PPAR $\alpha$ : peroxisome proliferator-activated receptors $\alpha$; SREBP-2: sterol regulatory element binding protein-2; FP: forward primer; RP: reverse primer

${ }^{2}$ The optimum ratio of primers and competimers of $\beta$-actin adopted when carrying out the semiquantitative PCR for the target genes

\section{Statistical analysis}

Data generated were analysed using one-way analysis of variance by SPSS 11.0 software with post hoc analyses being carried out by Tukey's honestly significant difference test. Differences between groups were considered statistically significant at $\mathrm{P}<0.05$.

\section{RESULTS}

Growth performance and body composition. Table 2 demonstrated that GlyGln could not only significantly increase the body weight of Yue-Huang broilers but also showed an energy re-distributional function with enhanced BMY and LMY and a declined AFP in a dose-dependent manner.

Table 2. Growth performance and body composition of the Yue-Huang broilers ${ }^{1}$

\begin{tabular}{lcccc}
\hline & \multicolumn{4}{c}{ Body weight, g/bird, $\mathrm{n}=3$} \\
\cline { 2 - 4 } \multicolumn{1}{c}{ Weeks } & 3 & 5 & 7 & 10 \\
\hline Control (0) & $289.75 \pm 4.96^{\mathrm{a}}$ & $477.86 \pm 13.75^{\mathrm{a}}$ & $761.05 \pm 25.44^{\mathrm{a}}$ & $1277.71 \pm 21.56^{\mathrm{a}}$ \\
LCG & $299.78 \pm 5.00^{\mathrm{b}}$ & $497.42 \pm 12.73^{\mathrm{b}}$ & $828.50 \pm 23.03^{\mathrm{b}}$ & $1321.59 \pm 22.88^{\mathrm{a}}$ \\
HCG & $299.80 \pm 4.23^{\mathrm{b}}$ & $494.72 \pm 13.15^{\mathrm{b}}$ & $804.17 \pm 21.78^{\mathrm{b}}$ & $1343.07 \pm 22.89^{\mathrm{b}}$ \\
\cline { 2 - 3 } & \multicolumn{3}{c}{ Body composition at week 10\%, n=20 } \\
\cline { 2 - 4 } & \multicolumn{2}{c}{ BMY } & AFP & \\
\cline { 2 - 4 } Control (0) & $17.32 \pm 1.12^{\mathrm{a}}$ & $10.32 \pm 0.42^{\mathrm{a}}$ & $3.24 \pm 0.22^{\mathrm{a}}$ & \\
LCG & $18.87 \pm 0.26^{\mathrm{b}}$ & $11.13 \pm 0.29^{\mathrm{b}}$ & $2.88 \pm 0.22^{\mathrm{b}}$ & \\
HCG & $19.74 \pm 0.78^{\mathrm{b}}$ & $12.37 \pm 0.22^{\mathrm{b}}$ & $2.83 \pm 0.23^{\mathrm{b}}$ & \\
\hline
\end{tabular}

${ }^{1}$ all the broilers received with starter feed supplemented with 0 (control), 0.01 (LCG) or 0.05 (HCG) mg glycyl-glutamine (Gly-Gln) per kg for 5 weeks, then given grower feed for 5 weeks. BMY: breast muscle yield; LMY: leg muscle yield; AFP: abdominal fat percentage

a,b means within the same vertical column that do not share a common superscript letter were significantly different $(\mathrm{P}<0.05)$ 
Serum and tissue parameters. It can be seen from the Table 3 that Gly-Gln could dose-dependently decrease the serum concentration of TG. However, only $0.01 \mathrm{mg}$ Gly-Gln significantly lowered the liver TG content. The concentration of T-CHO in sera and PM were dose-dependently decreased by Gly-Gln supplementation. In comparison with the control, $0.05 \%$ Gly-Gln treated group confirmed the wighest decreased level of 41.4 and $53 \%$ in relation to $\mathrm{T}-\mathrm{CHO}$ concentration in serum and PM respectively.

Table 3. TG and T-CHO concentrations in the sera and tissues from the Yue-Huang broilers ${ }^{1}$

\begin{tabular}{lccccc}
\hline & \multicolumn{2}{c}{ TG } & & \multicolumn{2}{c}{ T-CHO } \\
\cline { 2 - 3 } \cline { 5 - 6 } & sera, mmol/1 & liver, $\mathrm{mg} / \mathrm{g}$ & & sera, mmol/1 & PM, mg/g \\
\hline 0 & $0.84 \pm 0.05^{\mathrm{a}}$ & $25.99 \pm 3.52^{\mathrm{a}}$ & & $3.17 \pm 0.20^{\mathrm{a}}$ & $1.04 \pm 0.26^{\mathrm{a}}$ \\
LCG & $0.71 \pm 0.04^{\mathrm{ab}}$ & $13.25 \pm 1.74^{\mathrm{b}}$ & & $2.51 \pm 0.19^{\mathrm{b}}$ & $0.69 \pm 0.12^{\mathrm{ab}}$ \\
HCG & $0.69 \pm 0.04^{\mathrm{b}}$ & $21.16 \pm 4.87^{\mathrm{ab}}$ & & $1.86 \pm 0.14^{\mathrm{c}}$ & $0.49 \pm 0.04^{\mathrm{b}}$ \\
\hline
\end{tabular}

${ }^{1}$ all the broilers received with starter feed supplemented with 0 (control), 0.01 (LCG) or 0.05 (HCG) mg glycyl-glutamine (Gly-Gln) per kg for 5 weeks, then given grower feed for 5 weeks. TG: triglyceride; T-CHO: total cholesterol; PM: pectoralis major muscle. The data were expressed as means \pm SEM $(n=20)$; ${ }^{a, b}$ means within the same vertical column that do not share a common superscript letter were significantly different $(\mathrm{P}<0.05)$

Hepatic PPAR- $\alpha, A C C$ and SREBP-2 mRNA expression. The mRNA expression level of ACC and SREBP-2 in the liver of Yue-Huang broilers could be dosedependently down-regulated by Gly-Gln treatment (Figure 1B,C), while that of PPAR- $\alpha$ was up-regulated (Figure 1A). All the mRNA expression level showed significant difference in $0.05 \mathrm{mg} / \mathrm{kg}$ Gly-Gln treated group compared to the control group.

A

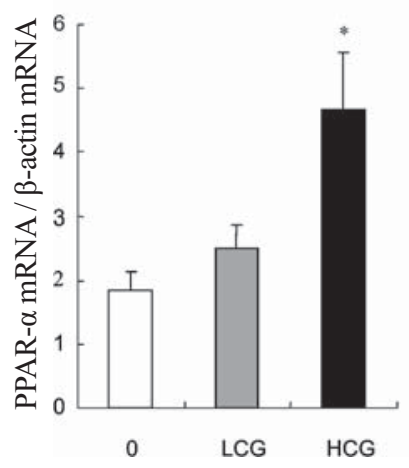

B

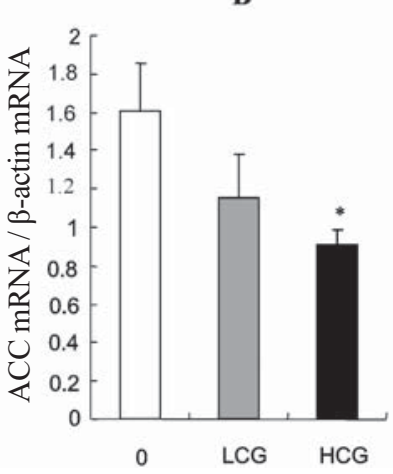

C

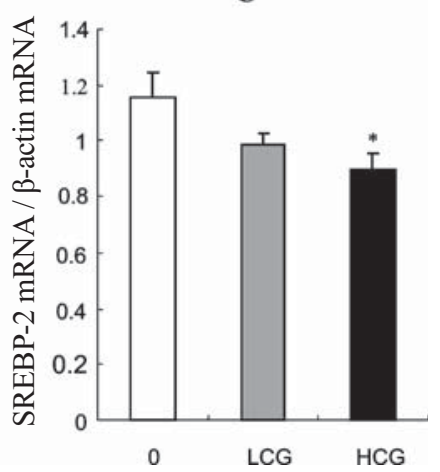

Figure 1. The mRNA expression levels of PPAR- $\alpha$ (A), ACC (B) and SREBP (C) in the liver of $45 \mathrm{~d}$ Yue-Huang broilers. All the birds offered with starter feed supplemented with 0 (control), 0.01 (LCG) or 0.05 (HCG) mg glycyl-glutamine (Gly-Gln) per kg for 5 weeks, then given grower feed for 5 weeks. PPAR- $\alpha$ : peroxisome proliferator-activated receptors $\alpha$; ACC: acetyl-CoA carboxylase; SREBP-2: sterol regulatory element binding protein-2. Each bar represents mean \pm S.E.M $(n=10)$. The asterisk above each bar indicates statistically significant $(\mathrm{P}<0.05)$ differences between the experimental group and control 


\section{DISCUSSION}

Muscle tissue is a major site for glutamine synthesis in animals and contains over $90 \%$ of the whole-body glutamine pool (Newsholme and Parry-Billings, 1990; Newsholme et al., 2003). The release of glutamine from skeletal muscle is stimulated during stress conditions such as injury and burns (Hammarqvist et al., 2001). This process could be reversed by the nutritional support of glutamine (Roth et al., 1988). Our present study showed that Gly-Gln supplementation resulted in an increase of BMY, LMY and the body weight of birds which is similar to the observations made in rats (Tannuri et al., 2000) and pig (Huang et al., 2004). An earlier study demonstrated an enhanced shearing strength of pectoralis major muscle in yellow-feathered chickens treated with Gly-Gln (Shu et al., 2006). The above observations give the indication that Gly-Gln could enhance avian protein deposition, probably, through decreasing the amino acids mobilization in muscles.

In this study, the energy re-distributional function of Gly-Gln was also indicated by way of a decreased AFP in Yue-Huang broilers. As expected, the concentration of TG and T-CHO in serum and the deposition of these in adipose and muscle tissue were significantly reduced with Gly-Gln supplementation, which suggest an important role of Gly-Gln in the avian lipid metabolism. In rodent, it has been reported that L-glutamine supplementation of a high fat diet attenuates hyperglycaemia and hyperinsulinaemia in C57BL/6J mice (Opara et al., 1996). Moreover, Xia et al. (2003) revealed that glutamine, as a major nutrient, could increased abundance of the mRNAs encoding the metabolic enzymes in mouse, muscle carnitine palmitoyl transferase I and muscle adenylosuccinate synthetase. In avian, however, the lipid metabolism is much different from mammal and rodent. About $80-85 \%$ of TG (Griffin et al., 1992) and 90\% of the total T-CHO (Qureshi et al., 1983) were reportedly de novo synthesized by the liver of chickens. During the synthesis of TG and cholesterol in liver, key enzymes and their transcript factors are closely associated with the body's fat deposit level. ACC, a rate-limiting enzyme, catalysed the first step for the synthesis of fatty acid. ACC defective mice showed a $50 \%$ decrease in their body fat deposit level (Abu-Elheiga et al., 2001; Tong, 2005). Peroxisome proliferator-activated receptors (PPARs) are a key family of nuclear transcription factors which participate in the process of lipid homeostatic regulations (Issemann and Green, 1990). The activation of PPAR- $\alpha$ in liver could promote ingestion, combination, and oxidized metabolism of fatty acid (Bocher et al., 2002). As a major regulation and control factor for T-CHO homeostasis, SREBP-2 promotes intake and synthesis of T-CHO in liver (Eberle et al., 2004). In this study, we found that Gly-Gln could dose-dependently downregulate ACC and SREBP-2 mRNA expression, but up-regulate that of PPAR- $\alpha$. It could be stated that Gly-Gln might reduce the de novo synthesis of fatty acids and 
cholesterol in the liver and thus, increase fatty acids oxidization which invariably would bring about the decline of fat and cholesterol deposition. For the crucial bioactivities of cholesterol (Saini et al., 2004), the content of T-CHO in animal products have been regarded as an important reference indices to evaluate meat qualities. This study may hopefully provide a favourable basis for low cholesterol meat production.

Though the mRNA expressions of avian hepatic lipid metabolism related genes were regulated by Gly-Gln supplementation, the exact mechanism remains unclear. Recently, Gly-Gln, which is also called $\beta$-endorphin (30-31), was identified as a neuron dipeptide generated from the two amino acids at the carboxyl terminal of $\beta$-endorphin 1-31 and belongs to the proopiomelanocortin (POMC) system (Krude and Gruters, 2000). Several lines of evidences suggested a wide range of biological activities of Gly-Gln, which can not only participate in immunological regulation, stimulate lymphocytosis, improve activities of natural killer cells (Ghanta et al., 1991), but also inhibit the dependence on opioid drugs (Cavun et al., 2005). Now that the physiological function of thermogenesis and energy equilibrium of POMC system has been well established (Low, 2004), whether the effects of Gly-Gln on the avian lipid metabolism act through the single Gln or the neuropeptide remains to be investigated.

\section{ACKNOWLEDGEMENTS}

We are grateful to Dr. Paul for his reading of this manuscript.

\section{REFERENCES}

Abu-Elheiga L., Matzuk M.M., Abo-Hashema K.A., Wakil S.J., 2001. Continuous fatty acid oxidation and reduced fat storage in mice lacking acetyl-CoA carboxylase 2. Science 291, 26132616

Bocher V., Pineda-Torra I., Fruchart J.C., Staels B., 2002. PPARs: transcription factors controlling lipid and lipoprotein metabolism. Ann. N.Y. Acad. Sci. 967, 7-18

Cavun S., Goktalay G., Millington W.R., 2005. Glycyl-Glutamine, an endogenous (beta)-endorphin derived peptide, inhibits morphine conditioned place preference, tolerance, dependence and withdrawal. J. Pharmacol. Exp. Ther. 315, 949-58

Chang T., Lu R., Tsai L., 2001. Glutamine ameliorates mechanical obstruction-induced intestinal injury. J. Surg. Res. 95, 133-140

Dieffenbach C.W., Dveksler G.S., 2004. PCR Primer: A Laboratory Manual. $2^{\text {nd }}$ Edition. Cold Spring Harbor Laboratory Press, pp. 167-185

Eberle D., Hegarty B., Bossard P., Ferre P., Foufelle F., 2004. SREBP transcription factors: master regulators of lipid homeostasis. Biochimie 86, 839-848

Furst P., Pogan K., Stehle P., 1997. Glutamine dipeptides in clinical nutrition. Nutrition 13, 731-737 
Ghanta V.K., Rogers C.F., Hsueh C.M., Hiramoto N.S., Soong S.J., Hiramoto R.N., 1991. In vivo enhancement of NK cell activity with met-enkephalin and glycyl-glutamine: their possible role in the conditioned response. Int. J. Neurosci. 61, 135-143

Griffin H.D., Guo K., Windsor D., Butterwith S.C., 1992. Adipose tissue lipogenesis and fat deposition in leaner broiler chickens. J. Nutr. 122, 363-368

Hammarqvist F., Ejesson B., Wernerman J., 2001. Stress hormones initiate prolonged changes in the muscle amino acid pattern. Clin. Physiol. 21, 44-50

Huang G.Q., Fu W.L., Gao P., Zhang X.Q., Zhang C.M., 2004. Effect of dipeptide glycyl-glutamine on the growth performance and endocrine function of weaned piglet. Chinese J. Anim. Sci. 40, $11-13,17$

Issemann I., Green S., 1990. Activation of a member of the steroid hormone receptor superfamily by peroxisome proliferators. Nature 347, 645-650

Krude H., Gruters A., 2000. Implications of proopiomelanocortin (POMC) mutations in humans: the POMC deficiency syndrome. Trends Endocrinol. Metab. 11, 15-22

Low M.J., 2004. Role of proopiomelanocortin neurons and peptides in the regulation of energy homeostasis. J. Endocrinol. Invest. 27, 95-100

Melis G.C., der Wengel N., Boelens P.G., van Leeuwen P.A., 2004. Glutamine: recent developments in research on the clinical significance of glutamine. Curr. Opin. Clin. Nutr. Metab. Care 7, 5970

Morlion B.J., Stehle P., Wachtler P., Siedhoff H.P., Koller M., Konig W., Furst P., Puchstein C., 1998. Total parenteral nutrition with glutamine dipeptide after major abdominal surgery: a randomized, double-blind, controlled study. Ann. Surg. 227, 302-308

Nemoto A., Krajack A., Suzuki T., Takeyoshi I., Hamada N., Nomoto M., Zhang S., Zhu Y., Starzl T.E., Todo S., 1996. Glutamine metabolism of intestine grafts: influence of mucosal injury by prolonged preservation and transplantation. Transplant P 28, 2545-2546

Newsholme E.A., Parry-Billings M., 1990. Properties of glutamine release from muscle and its importance for the immune system. J. Parent. Enter. Nutr. 14, 63S-67S

Newsholme P., Lima M.M., Procopio J., Pithon-Curi T.C., Doi S.Q., Bazotte R.B., Curi R., 2003. Glutamine and glutamate as vital metabolites. Braz. J. Med. Biol. Res. 36, 153-163

Opara E.C., Petro A., Tevrizian A., Feinglos M.N., Surwit R.S., 1996. L-glutamine supplementation of a high fat diet reduces body weight and attenuates hyperglycemia and hyperinsulinemia in C57BL/6J mice. J. Nutr. 126, 273-279

Petersson B., von der Decken A., Vinnars E., Wernerman J., 1994. Long-term effects of postoperative total parenteral nutrition supplemented with glycylglutamine on subjective fatigue and muscle protein synthesis. Brit. J. Surg. 81, 1520-1523

Powell-Tuck J., 1999. Total parenteral nutrition with glutamine dipeptide shortened hospital stays and improved immune status and nitrogen economy after major abdominal surgery. Gut 44, 155

Qureshi A.A., Abuirmeileh N., Din Z.Z., Elson C.E., Burger W.C., 1983. Inhibition of cholesterol and fatty acid biosynthesis in liver enzymes and chicken hepatocytes by polar fractions of garlic. Lipids 18, 343-348

Roth E., Karner J., Ollenschlager G., Karner J., Simmel A., Furst P., Funovics J., 1988. Alanylglutamine reduces muscle loss of alanine and glutamine in post-operative anaesthetized dogs. Clin. Sci. 75, 641-648

Saini H.K., Arneja A.S., Dhalla N.S., 2004. Role of cholesterol in cardiovascular dysfunction. Can. J. Cardiol. 20, 333-346

Shu G., Gao P., Zhu X.T., Jiang Q.Y., Wang Z.G., Fu W.L., 2006. The effect of glycyl-glutamine on meat quality of Yuehuang broilers. J. South China Agr. Univ. 27, 92-95 
Tannuri U., Carrazza F.R., Iriya K., 2000. The effects of glutamine-supplemented diet on the intestinal mucosa of the malnourished growing rat. Rev. Hosp. Clin. Fac. Med. Sao Paulo 55, 87-92

Tong L., 2005. Acetyl-coenzyme A carboxylase: crucial metabolic enzyme and attractive target for drug discovery. Cell. Mol. Life Sci. 62, 1784-1803

Van der Hulst R.R., Van Kreel B.K., Von Meyenfeldt M.F., Brummer R.J., Arends J.W., Deutz N.E., Soeters P.B., 1993. Glutamine and the preservation of gut integrity. Lancet 341, 1363-1365

Xia Y., Wen H.Y., Young M.E., Guthrie P.H., Taegtmeyer H., Kellems R.E., 2003. Mammalian target of rapamycin and protein kinase A signaling mediate the cardiac transcriptional response to glutamine. J. Biol. Chem. 278, 13143-13150 